\title{
DELIBERAÇÃO E CONTROLE SOCIAL: UM PERFIL DOS CONSELHOS ESTADUAIS DE POLÍTICAS PÚBLICAS NO NORDESTE BRASILEIRO
}

\author{
André Luis Nogueira da Silva ${ }^{1}$ \\ Damião Ernane de Soura ${ }^{2}$
}

\begin{abstract}
Resumo:
A redemocratização e a definição de um novo modelo federativo brasileiro, advindos com a Constituição de 1988, promoveram uma profunda modificação no sistema político nacional, com a instituição de três entes federados, criação de novos arranjos institucionais e a inserção de novos atores sociais nas etapas de planejamento, formulação e monitoramento das ações governamentais. Grande parte dos estudos que tratam sobre as instituições participativas brasileiras focalizam a esfera municipal, havendo carência de pesquisas sobre os governos estaduais, seu modo de funcionamento, áreas de atuação e existência de controle social. Com base na ESTADIC Pesquisa de Informações Básicas Estaduais e nas informações do Portal da Transparência, procedeu-se a um estudo comparativo dos estados do Nordeste quanto ao controle social e ao volume de transferências federais discricionárias em dezesseis áreas de políticas públicas. O objetivo foi de esboçar um perfil dos Conselhos estaduais de políticas públicas, analisando suas características à luz da teoria deliberativa e dos estudos sobre Conselhos de políticas no Brasil. Os dados sugerem a necessidade de aperfeiçoamento dos conselhos estaduais do Nordeste. As deficiências em características básicas para seu funcionamento restringem seu potencial de qualificar as decisões por meio de um diálogo público consciente e com a presença de ideias concorrentes. Diante deste cenário, o governo federal aparece como ator fundamental, podendo induzir a criação e o aprimoramento destes espaços institucionalizados de participação.
\end{abstract}

Palavras-chave: democracia deliberativa; controle social; conselhos estaduais; políticas públicas.

\section{Resumen:}

La democratización e la definición de un nuevo modelo federativo brasileño, que viene con Constitución de 1988, promovió un cambio profundo en el sistema político nacional post-1988 con la creación de tres niveles federados, la creación de nuevos arreglos institucionales y la inserción de nuevos actores sociales en las etapas de planificación, formulación y seguimiento de las acciones gubernamentales. La mayoría de los estudios que se ocupan de las instituciones participativas brasileñas se centran en el nivel municipal, hay una falta de investigación sobre los gobiernos de los estados, su modo de operación, áreas de trabajo y la existencia de control social. Basado en Pesquisa de Informações Básicas Estaduais - ESTADIC y las informaciones en el Portal de la Transparencia, se procedió a un estudio comparativo de los estados del nordeste como el control social y volumen de las transferencias federales discrecionales en dieciséis áreas de la política pública. El objetivo era trazar un esbozo de los Consejos estatales de políticas públicas, el análisis de su características a la luz de la teoría deliberativa y los estudios de Consejos de políticas públicas de Brasil. La datos sugieren la necesidad de mejorar los consejos estatales del Nordeste. Las deficienc ias en las funciones básicas de su funcionamiento restringen su potencial para calificar las decisiones a través de un diálogo consciente y público con la presencia de las ideas que compiten. En este escenario, el gobierno federal se presenta como un actor clave que puede inducir a la creación y mejora de estos espacios institucionalizados de participación.

Palabras-clave: democracia deliberativa, el control social, los consejos estatales, políticas públicas.

\footnotetext{
${ }_{1}^{1}$ Mestrando do Programa de Pós-Graduação em Estudos Urbanos e Regionais da UFRN e Analista de Planejamento do IBGE/RN

2 Doutor em Saúde Pública pelo ISC/UFBA e Analista de Gestão em Pesquisa do IBGE/RN
} 


\section{Abstract:}

The democratization and the definition of a new brazilian federative model, coming with Constitution of 1988, promoted a profound change in the national political system post-1988 with the establishment of three federated level, the creation of new institutional arrangements and the insertion of new social actors in the stages of planning, formulation and monitoring government. Most studies that deal about the Brazilian participatory institutions focus on the municipal level, there is lack of research on state governments, its mode of operation, areas of action and the existence of social control. Based on the Pesquisa de Informações Básicas Estaduais - ESTADIC and on the information in the Portal da Transparência, proceeded to a comparative study of the Northeastern states on the social control and on the volume of discretionary federal transfers in sixteen areas of public policy. The aim was to sketch an profile of the state Councils of public policies, analyzing their characteristics in the light of deliberative theory and of studies about Councils policies in Brazil. The data suggest the need to improvement the state councils of the Northeast. The deficiencies in basic features to its functioning restrict their potential to qualify the decisions across a conscious public dialogue and with the presence of competing ideas. In this scenario, the federal government appears as a key actor to induce the creation and the improvement of these institutionalized spaces of participation.

Keywords: deliberative democracy, social control, state councils, public policies.

\section{INTRODUÇÃO}

A redemocratização e a instituição de um novo modelo federativo brasileiro, advindos com a Constituição de 1988, promoveram uma profunda modificação no sistema político nacional. Ao mesmo tempo em que se instituíram três entes federados, novos arranjos institucionais foram sendo criados como forma de inserir atores sociais no processo de planejamento, formulação e monitoramento das ações governamentais. A democracia brasileira revigorava-se, não apenas com o retorno das eleições para o executivo federal, mas também com a perspectiva de que a participação social poderia "inverter a ordem de prioridades", melhorando a vida dos mais necessitados (GOHN, 2004).

Com este sentimento, incorporaram-se à estrutura dos governos os Conselhos gestores de políticas públicas. A disseminação destes espaços ocorreu muito em virtude da “indução promovida por processos de descentralização que condicionavam a transferência de recursos financeiros federais para os níveis subnacionais de governo" (CÔRTES, 2007, p. 137). Os Conselhos, assim, passaram a compor o arranjo institucional das políticas sociais à medida que elas se constituíam em sistemas nacionais. A instalação de conselhos tornou-se requisito obrigatório para adesão a programas como SUS (saúde), FUNDEF/FUNDEB (educação) e SUAS (assistência social) ${ }^{3}$. Tal condicionante atendia

\footnotetext{
${ }^{3}$ Convém explicitar que a inserção dos Conselhos às estruturas da gestão pública brasileira acompanhou o desenvolvimento institucional de cada setor. Assim, o momento de sua criação e sua forma de funcionamento possuem especifidades inerentes a cada estado e município.
} 
os preceitos constitucionais, bem como a reivindicação dos movimentos sociais, que enxergavam nestes canais a possibilidade de democratizar a tomada de decisão e de identificar as demandas da população local. Ou seja, acreditavam que os Conselhos poderiam influenciar as políticas públicas.

No mesmo período de expansão dos Conselhos pelo território nacional, década de 1990, começa a surgir uma teoria democrática alternativa, que questionava não apenas a democracia representativa, mas também punha dúvidas à capacidade da democracia participativa em melhorar a vida da população. Tendo como subsídio filosófico as ideias de Habermas, a teoria deliberativa propõe outro caminho para melhoria das decisões públicas. Para os defensores desta corrente, as decisões advindas de um intenso e consciente diálogo público seriam mais responsivas às demandas sociais.

Por se constituírem em espaços que congregavam atores sociais e estatais, e que pressupunham discussões para tomada de decisão, alguns estudiosos passaram a tentar encontrar vestígios deliberativos nos Conselhos de políticas públicas (CUNHA, 2007). No entanto, são muitos os trabalhos que apontam para ineficácia destas instâncias na simples promoção da participação social, quem dirá concebê-las enquanto canal deliberativo. Seus resultados demonstram que a mera existência de um arranjo participativo é insuficiente para ampliar a responsividade dos governos aos anseios populares (TATAGIBA, 2002; DAGNINO, 2002; GOHN, 2004; CÔRTES, 2007).

A maioria das pesquisas que tratam sobre as instituições participativas brasileiras possui como objeto de estudo os experimentos municipais. A importância angariada pelos municípios com a nova organização do Estado brasileiro parece ter canalizado os próprios interesses investigativos para aquela esfera de governo. A carência de pesquisas sobre os governos estaduais é patente também em outros quadros analíticos (SOUZA, 2003). A compreensão sobre a sua forma de funcionamento, suas áreas de atuação, a existência de mecanismos de controle social e o seu caráter ainda são uma incógnita para a Ciência Política. Visando subsidiar investigações sobre este ente governamental, o Instituto Brasileiro de Geografia e Estatística (IBGE) lançou em 2012 a Pesquisa de Informações Básicas Estaduais (ESTADIC). Investigando inúmeras informações sobre a estrutura administrativa dos governos estaduais, o levantamento trouxe interessantes indicadores que permitem traçarmos um perfil dos Conselhos estaduais de políticas públicas no Brasil. Desta feita, usando os referidos dados e confrontando-os com informações de repasses federais, extraídas do Portal da Transparência, tentaremos esboçar um perfil dos Conselhos 
estaduais de políticas públicas, analisando suas características à luz da teoria deliberativa e dos estudos sobre Conselhos de políticas no Brasil.

Com este fim, o trabalho, inicialmente, discutirá sobre a teoria deliberativa, apontando os principais argumentos utilizados pelos teóricos em sua defesa. Tratará, ainda, sobre a deliberação no Brasil, enfatizando o modo como os Conselhos vêm atuando na gestão pública brasileira. Em seguida, detalhará a metodologia utilizada para coleta, organização e análise dos dados. Posteriormente, será construído um perfil dos Conselhos de políticas públicas estaduais do Nordeste, demonstrando sua desqualificação enquanto mecanismo deliberativo. Por fim, algumas considerações de caráter conclusivo serão colocadas.

\section{A DEMOCRACIA DELIBERATIVA}

A teoria democrática viu-se, durante muitos anos, restrita a uma discussão quase que dualista envolvendo em suma duas perspectivas: a que exacerba o caráter instrumental da democracia e a que eleva o feitio substantivo do processo democrático. A primeira é enfatizada pelos democratas liberais ao superestimarem o valor procedimental da democracia, sustentando que ela protege as liberdades individuais das arbitrariedades do Estado. A segunda, maximizada pela democracia participativa, identifica o caráter pedagógico da prática democrática como sua principal herança. Dessa forma, a aproximação do Estado com a sociedade deveria ser encurtada, com a criação de mecanismos que facilitassem a participação direta dos indivíduos nas decisões governamentais. A institucionalização destes espaços públicos presumiria uma maior efetividade das políticas públicas.

Confrontando tal dualismo, surge, ao longo da década de 1990, uma nova concepção democrática cuja preocupação recai sobre o resultado das decisões públicas. A ideia é que a democracia não pode ser avaliada pela simples abrangência do "demos" ou pela existência de mecanismos de participação direta. Estes não seriam suficientes para ampliar a melhoria da qualidade de vida da população. Refletindo sobre tal situação, autores como Elster (2007), Held (2006) e Fishkin (2005) defendem a incorporação da deliberação nos espaços de participação, como forma de "qualificar a tomada de decisão".

Para Fishkin (2005), a democracia mundial tem se direcionado cada vez mais para uma maior utilização de instrumentos de democracia direta. No entanto, à medida que estas práticas vem aumentando, as deliberações vêm decaindo. $O$ autor entende como deliberação o levantamento de considerações concorrentes dentro de uma discussão 
pública. Seu diagnóstico é que a "participação pela participação" pode culminar com uma decisão contrária à melhoria da vida das pessoas. Sendo assim, para que haja deliberação é necessário que os cidadãos/participantes sejam informados, equilibrados, conscientes, compreensivos e que possuam argumentos substantivos. Apenas assim, as deliberações públicas trariam efeitos positivos para a sociedade.

Além de questionar a eficácia da clássica democracia direta, Fishkin (2005) também ataca a democracia representativa, afirmando não haver deliberação dentro do próprio parlamento. Segundo ele, as decisões parlamentares são constrangidas pelas negociações, pelas orientações partidárias e pela situação política do parlamentar (situação ou oposição). Diante deste cenário, é a população quem possui maior capacidade de deliberação, pois aparece com maior autonomia para tomada de decisão. Além disso, coloca que "is unlikely to change very much. Not for the public as a whole, at least." (FISHKIN, 2005, p. 286). A concentração de decisões no parlamento dificulta mudanças mais profundas, o que poderia ser suplantado por fóruns deliberativos.

O autor continua sua defesa da deliberação, ao apresentar a fragilidade das votações convencionais, percebidas como cognitivamente triviais. Este mecanismo acaba por extrair opiniões desprovidas de compreensão e reflexão. Propõe, assim, o instituto da Sondagem Deliberativa, pois "exposing random samples to balanced information, encouraging them to weigh opposing arguments in discussions with heterogeneous interlocutors, and then harvesting their more considered opinions" (FISHKIN, 2005, p.287). A escolha dos participantes se daria por meio de uma amostra selecionada aleatoriamente. A ideia é que os escolhidos sejam dotados de grande representatividade da população. O que resolveria o problema da equidade política, vez que todos possuiriam a mesma possibilidade de participar do processo deliberativo. ${ }^{4}$

$\mathrm{Na}$ mesma direção deliberativa, Held (2006) apresenta, em "Deliberative Democracy and the Defence of the Public Healm", seus argumentos em prol da nova corrente democrática. $\mathrm{O}$ autor coloca que, ao contrário do que apregoam os liberais, o bem comum é muito mais do que uma agregação de preferências individuais. Trata-se de um interesse coletivo, construído a partir do diálogo público racional e consciente. ${ }^{5}$ Ele acredita

\footnotetext{
${ }^{4}$ Este parece ser o argumento mais problemático de Fishkin (2005). A falta de definição do conceito de "população", dificulta a indicação de critérios para estipulação de uma amostra representativa. A indefinição parece proposital, vez que a sondagem deliberativa é proposta para qualquer nível de governo. Neste sentido, tendemos a conceber que a seleção da amostra deve se pautar, pelo menos, por critérios demográficos, que garantam a representatividade espacial.

${ }^{5}$ Esta é a concepção de bem comum encontrada em ELSTER (2007), HELD (2006) e FISHKIN (2005).
} 
que as decisões governamentais falham por não considerarem o fato, o futuro e o outro (fact-regarding, future-regarding e other-regarding). A deliberação resolveria este problema, pois teria como resultado uma preferência refinada e reflexiva. Para Held (2006 p. 234),

The upshot of the argument, then, is that democratic theory needs to think not just about the contexts in which people form views and test their opinions, but also about the kinds of mechanisms that are in operation in democracies that either reinforce existing viewpoints, or help create new ones.

Como visto, outro benefício da deliberação seria sua elevada capacidade de originar novas ideias. A defesa da democracia deliberativa supõe, como já dito, a insuficiência da democracia representativa. $\mathrm{O}$ autor cita uma passagem sarcástica de Fishkin que afirma que a escolha de candidatos se dá de forma similar à escolha por detergentes. Demonstra, ainda, que o modelo político contemporâneo torna o eleitor alienado, desengajado e complacente, o que facilita a liderança das elites nos assuntos públicos.

Held (2006) apresenta também o pensamento de Elster sobre o sistema democrático contemporâneo, influente inclusive nas ideias de Fishkin. Para Elster (apud HELD, 2006), a perspectiva da política enquanto agregador de preferências privadas utilizase de um conceito de racionalidade apropriado para compreensão das relações de mercado, o que não é o caso. A ideia é que a ação dos indivíduos no mercado é decidida com a perspectiva das questões que afetam apenas eles. A decisão em fóruns públicos, no entanto, envolve decisões que afetam toda a coletividade. Esta situação teria grande influência no resultado das decisões coletivas. Da mesma forma que Fishkin (2005), Elster (2007) também expõe as limitações da democracia direta, afirmando que ela não pode ser realizada nesta sociedade altamente complexa; que sua utilização em escalas locais tenderia ao surgimento de tiranias; e que a ampliação da participação maximizaria o problema da qualidade das decisões.

A esperança de Held (2006) na democracia deliberativa parte da sua capacidade transformacional. Ou seja, advém da crença de que as preferências individuais podem ser modificadas em processos de deliberação. Além disso, acredita que a deliberação permite expor a complexidade dos problemas e que ela pode fazer com que as decisões deixem de ser baseadas no interesse para que sejam orientadas pela razão.

Como já dito, Elster (2007) também aparece como um dos expoentes teóricos da democracia deliberativa. Em análise sobre concepções vigentes do sistema democrático, o 
autor apresenta criticamente três formulações teóricas, a saber: teoria da escolha social, teoria da discussão pública de Habermas e a democracia participativa. Enquanto a escolha social colocaria o ato político como produto do confronto entre interesses privados, as outras duas correntes negariam o caráter privado do comportamento político.

Posta pelo autor como "teoria mercadológica da política", a teoria da escolha social exacerba o individualismo, colocando como impossível a existência de proposições consensuais. Para seus teóricos, o sistema deve permitir a ordenação de preferências em meio a alternativas e a escolha deve sempre recair entre duas opções. Assim, as preferências sociais devem sempre respeitar os interesses individuais.

Elster critica tal concepção, propondo que as preferências individuais podem não representar a real preferência das pessoas, vez que o indivíduo pode não conhecer outras opções e realidades. Ademais, alguns métodos de agregação de preferência podem induzir os sujeitos a expressarem "preferências falsas". O mecanismo da escolha social, assim, seria inadequado como meio para decisões públicas, vez que a simples agregação de preferências individuais poderia afetar negativamente a população. Ao contrário das decisões de mercado, a tarefa da política não seria apenas eliminar a ineficiência - como apregoa os liberais - mas produzir justiça. Sendo assim, os princípios que norteiam uma decisão pública são distintos dos que orientam as relações privadas.

As proposições dos teóricos da democracia direta, como já dito, exacerbam o valor pedagógico da participação popular. A política, aqui, aparece como fim em si mesma. O maior problema da teoria estaria no "esquecimento" dos resultados das decisões, ou seja, o foco na participação acaba por colocar o produto das decisões em segundo plano, ou mesmo, tornando-o irrelevante. Assim, seus benefícios ou malefícios não importariam.

A perspectiva de Habermas tenta resolver o problema do fosso existente entre participação e resultado das decisões. Para a teoria da discussão pública, "O input do mecanismo da escolha social não seriam as preferências brutas, provavelmente egoístas e irracionais, que operam no mercado, mas as preferências informadas e orientadas para o outro" (ELSTER, 2007, p.232). Para o filósofo, o objetivo da política seria a consecução da unanimidade em meio a um debate público. Segundo ele, a simples existência de uma discussão coletiva sensibilizaria os participantes a tomarem decisões consensuais. Argumenta, para isso, que num debate público a defesa de interesses privados seria facilmente suplantada. A busca pelo bem comum, neste sentido, facilitaria a consecução de decisões consensuais. 
Mesmo expondo sua aproximação ao modelo preconizado por Habermas, Elster (2007) identifica problemas nas proposições do autor. Uma delas parte da ideia de que a obrigação em participar resultaria em um paternalismo e que, por outro lado, a sua não obrigatoriedade poderia criar uma "elite auto-eleita". Além desse problema da participação, a discussão poderia resultar em um efeito reverso, oposto ao bem comum. Ademais, a expressão de preferências sobre o bem comum, devido à fluidez deste conceito, não afasta a possibilidade do uso de argumentos egoístas nas deliberações.

Apesar disso, a principal crítica de Elster (2007) recai sobre a busca por consensos nas discussões públicas. Para ele, a existência da unanimidade seria decorrente da conformidade e não do acordo racional. $\mathrm{O}$ autor confia mais em decisões que possuem uma pequena minoria contrária, do que naquelas consensuais. Sua opinião advém do risco das decisões não demonstrarem uma preferência geral, pois pessoas podem concordar apenas como efeito mimético, ou mesmo porque sentem que estarão entre a minoria. Segundo Elster (2007, p.238) “[...] uma decisão coletiva é mais confiável quando for menos do que unânime".

Ainda tratando das críticas à Democracia Deliberativa, Fishkin (2005) apresenta algumas objeções à teoria que podem ser sintetizadas nos seguintes argumentos: as pessoas são incapazes de decidir sobre uma política pública; a deliberação é desnecessária, pois pode resultar em simples sugestões heurísticas; e a deliberação pode alterar preferências pela atuação de grupos mais preparados.

A partir da análise de experiências empíricas de sondagens deliberativas, o autor chegou a alguns padrões de comportamento: (1) os participantes são representativos; (2) opiniões frequentemente mudam; (3) intenções de voto frequentemente se alteram; (4) participantes ganham informação; (5) as mudanças de opinião e voto e as informações percebidas são relatadas; (6) as mudanças em opiniões e votos são alheios à posição social; (7) as atitudes políticas e as intenções de voto tendem a ser mais previsíveis, e há mais articulação sobre critérios normativamente mais desejáveis depois da deliberação do que antes. (8) aumento da simples priorização; (9) aumento na priorização e a consecução da informação são relatadas; (10) preferências não necessariamente se polarizam através da discussão em grupo; (11) preferências não necessariamente se homogeneízam dentro de grupos; (12) deliberações equilibradas tendem a promover uma aprendizagem equilibrada. (FISHKIN, 2005, p. 290-292). Tais conclusões enfraquecem as críticas à democracia deliberativa, a despeito de sua discussão dentro da filosofia política. 
O autor reivindica mais estudos sobre as experiências deliberativas, para que possamos analisar de fato qual seu impacto no sistema democrático atual. Para ele, antes da crítica por parte da filosofia política, a experiência prática é essencial para se estudar os efeitos dos empreendimentos deliberativos na democracia contemporânea.

Apesar de recente, a democracia deliberativa ainda carece de alguns aportes conceituais e empíricos para se fixar enquanto teoria. A pressuposição de que as preferências individuais podem ser afastadas em prol de um pensamento altruístico ou mesmo solidário ainda necessita de comprovação empírica. No entanto, as experiências apresentadas pelos autores parecem alimentar uma interessante reflexão sobre o futuro dos sistemas políticos no mundo. Se o instituto democrático parece não ser mais alvo de incertezas, seu desenho ainda parece incompleto ou insuficiente para atingir os anseios da sociedade. A democracia deliberativa, talvez, possa dar sua contribuição nesta direção.

\section{A DELIBERAÇÃO NO BRASIL}

Desde a Constituição de 1988 percebe-se um crescente avanço na criação de instituições híbridas, que congregam atores sociais e estatais, na gestão pública brasileira. Levantamento do IPEA (2010) aponta que até a promulgação da nova Constituição haviam sido realizadas apenas 12 conferências nacionais. De 2003 a 2010 há registro da realização de 74 discussões nacionais, em sua maioria organizadas pelo próprio ente público. Do início da década de 1990 até 2010 haviam sido criados 26 Conselhos Nacionais com vistas a promover a interação do Estado com a sociedade no planejamento, formulação e controle de políticas públicas.

No nível local, observou-se a criação de mais de 1500 Conselhos municipais de políticas públicas entre os anos de 2001 e 2009. O Orçamento Participativo é outra interface Estado/sociedade que vem se disseminando desde a redemocratização, sendo registradas 577 experiências municipais entre 1989 e 2008.

Em estudo comparativo entre os Conselhos de políticas e os Orçamentos Participativos, Cunha (2007) afirma que a criação destes espaços objetivava democratizar a tomada de decisão e servir como mecanismo de identificação de demandas da população. O autor parte do entendimento de que a deliberação "se concretiza em instituições que articulam sociedade e Estado, em que razões normativas são apresentadas por meio de procedimentos que expressam a soberania e legitimam as decisões tomadas nessas instituições" (CUNHA, 2007, p.28). Contraria as ideias de Habermas, ao afirmar que a 
unanimidade é desnecessária para legitimidade das decisões e para configuração de uma deliberação pública.

Sua conclusão indica que as instituições estudadas, mesmo que não consigam democratizar plenamente o processo decisório, vêm produzindo impacto nas relações de poder e na produção de políticas públicas. Elas cumprem objetivos distintos, que aproximam os conselhos da democracia deliberativa e os OP's da participativa.

A aproximação dos Conselhos de políticas com a perspectiva deliberativa parece um tanto quanto questionável. Nos últimos anos, estudos vêm ressaltando as limitações destes espaços na promoção da participação social, demonstrando problemas na sua forma de funcionamento, bem como na sua capacidade de influenciar as políticas públicas.

Buscando identificar até que ponto a ampliação dos espaços de participação no Brasil vem provocando efeitos nas ações governamentais, Tatagiba (2002) analisa inúmeras teses e dissertações que tratam sobre os conselhos de políticas. Sua ideia não é detalhar particularidades sobre este mecanismo participativo/deliberativo, mas buscar generalizações que possam contribuir para um diagnóstico destes canais de interação entre Estado e sociedade.

O objeto de estudo da autora são os conselhos de políticas ${ }^{6}$ municipais, entendidos como aqueles criados de forma compulsória, como obrigação legal para o repasse de recursos federais. Os conselhos seriam - ou deveriam ser - "espaços públicos de composição plural e paritária entre Estado e sociedade civil, de natureza deliberativa, cuja função é formular e controlar a execução das políticas públicas setoriais" (TATAGIBA, 2002, p.54).

Característica essencial dos conselhos seria seu caráter paritário. Como sua função é permitir a existência de uma interface Estado/sociedade, seja para democratizar a tomada de decisão ou para se extrair as demandas da população, o equilíbrio entre governo e cidadãos apresenta-se como primordial para o exercício do que o conselho se propõe. Tal caráter torna-se mais importante quando se observa que mesmo existindo paridade o Estado continua a aparecer como protagonista na definição e priorização das políticas públicas, conseguindo na maioria das vezes sobrepor sua visão nas decisões dos conselhos.

A pluralidade na composição não estaria apenas relacionada a relação Estado/sociedade, mas também a clivagens internas dentro do próprio campo da política.

\footnotetext{
${ }^{6}$ A autora lança mão de uma tipologia usada pelo IBAM/IPEA (1997), que divide os Conselhos em três categorias: Conselhos de programas, vinculados a programas específicos e que surgem para ações emergenciais; Conselhos de políticas, previstos pela legislação e componente de políticas públicas mais estruturadas e concretizadas em sistemas nacionais; e Conselhos temáticos, que são criados por iniciativa municipal ou estadual
} 
Um dos principais desafios, então, seria a existência de mecanismos que permitissem que todos os representantes pudessem expressar e defender suas opiniões de forma a influenciar no resultado da deliberação. Devido à publicização permitida pelos conselhos, o resultado das discussões partiria não de acordos clientelistas e de troca de favores para obtenção de vantagens particulares, mas de processos deliberativos, que trariam a busca pelo bem comum para o centro do debate.

Para Tatagiba (2002, p.55), “a competência legal de deliberar sobre as políticas públicas é a principal força dos conselhos enquanto espaços potencialmente capazes de induzir à reforma democrática do Estado". Percebe-se, assim, que a capacidade de deliberação é fundamental para que o conselho consiga atuar da forma como se propõe. No entanto, a autora observou que a resolução dos conflitos no interior dos conselhos não ocorre a partir de debates de ideias ou políticas públicas. Muito pelo contrário, os estudos vêm apontando para uma dificuldade na explicitação dos interesses por parte dos representantes e na falta de reconhecimento da troca de ideias como meio para tomada de decisão. Além disso, alguns assuntos não entram na pauta de deliberação porque ainda não está bem definido o lugar dos conselhos na estrutura governamental - decisões imperativas ou consultivas - e porque ainda há visível controle do Estado na definição de sua agenda. Esta situação constrange a atuação dos conselhos, afetando sua autonomia - argumento da teoria deliberativa para tomada de decisão a partir de diálogos públicos.

Tratando sobre o resultado das deliberações, Tatagiba (2002) coloca que para democratização da gestão pública não há que se falar em "poder consultivo" dos Conselhos. Seu potencial democratizante advém tanto da sua capacidade de deliberação sobre os assuntos públicos quanto do controle social a partir da fiscalização dos recursos. A junção das duas funções apareceria como uma feliz combinação para o avanço democrático.

As pesquisas vêm apontando para o descumprimento da vocação deliberativa por parte dos Conselhos. Em sua maioria, os estudiosos argumentam que estes espaços acabam mais eficazes na inibição da transgressão por parte do Estado, por meio da fiscalização, do que influenciando políticas públicas. Neste sentido, se uma das principais atribuições destas instituições é o controle social, a criação de fundos propiciaria maior transparência e monitoramento dos gastos públicos, vez que sua gestão caberia ao Conselho.

Parte deste ponto a principal conclusão da autora. Segunda ela, os Conselhos vêm apresentando "baixa capacidade propositiva" (TATAGIBA, 2002, p.98), atuando de forma mais consistente na fiscalização. Isto reduz o potencial democrático destas instituições, 
afastando-as, contrariando Cunha (2007), do ideário proposto pela teoria deliberativa.

O presente trabalho, no entanto, não pretende analisar até que ponto os conselhos de políticas do país se configuram enquanto experimento deliberativo. Demonstrada a sua importância, suas limitações e sua forma de funcionamento no sistema político brasileiro, pretende-se traçar um perfil dos conselhos de políticas em outro nível de governo.

Ainda carente de estudos por parte da Ciência Política, pouco ainda se conhece sobre a dinâmica de atuação dos governos estaduais (ABRUCIO, 1998; ARRETCHE, 1999; SOUZA, 2003; GONÇALVES, 2009), muito menos sobre os mecanismos de participação social inseridos em sua estrutura administrativa. A compreensão sobre o ente estadual mostra-se relevante pela falta de clareza sobre sua atuação no federalismo brasileiro. Visando contribuir com o preenchimento deste "vácuo científico", será construído, a seguir, um perfil dos Conselhos estaduais de políticas do Nordeste com base nas informações disponíveis pela ESTADIC (IBGE, 2012).

\section{MÉTODOS}

Trata-se de estudo comparativo dos estados do Nordeste quanto ao controle social e ao volume de transferências federais discricionárias em dezesseis áreas de políticas públicas. Para a análise do controle social nos Estados, representado pela existência de conselhos por áreas de políticas públicas e suas características, realizou-se um levantamento de dados secundários de natureza administrativa da ESTADIC - Pesquisa de Informações Básicas Estaduais do IBGE (2012). As informações sobre as transferências federais, por sua vez, foram coletadas no Portal da Transparência, mantido pelo governo federal.

\section{Pesquisa de Informações Básicas Estaduais do IBGE (ESTADIC)}

No primeiro semestre de 2012, foi realizada a ESTADIC nas 27 Unidades da Federação - 26 estados e o Distrito Federal. Trata-se de uma pesquisa cujo informante era a autoridade do executivo estadual, secretário de estado ou outro representante devidamente indicado pelo gestor para o fornecimento das informações. A coleta de dados foi realizada através de dois questionários - Questionário Básico e Suplemento de Assistência Social. O Questionário Básico coletou informações da gestão e equipamentos estaduais, dados sobre recursos humanos, existência de conselhos, suas características e respectivos fundos ${ }^{7}$, política de gênero, direitos humanos, segurança alimentar e nutricional

\footnotetext{
$7 \quad$ Fundo refere-se ao patrimônio de um ou mais entes públicos com uma finalidade específica,
} constituindo uma entidade contábil independente e sem personalidade jurídica. 
e inclusão produtiva. No suplemento sobre Assistência Social foram coletadas informações sobre a gestão da assistência social, que não serão utilizadas neste trabalho.

Para este estudo, foram analisadas as variáveis: existência de conselhos em dezesseis áreas temáticas (saúde, cultura, esporte, habitação, transporte, saúde, segurança pública, meio ambiente, criança e adolescente, idoso, pessoa com deficiência, igualdade racial, LGBT, gênero, segurança alimentar e direitos humanos), suas características (paritário, consultivo, deliberativo, normativo, fiscalizador, realização de reunião nos últimos doze meses), além da existência de fundo estadual na área de cada conselho.

De acordo com os critérios da ESTADIC (IBGE, 2012), o Conselho foi considerado como instrumento de fortalecimento da participação democrática da população na formulação e implementação de políticas públicas. Em relação às características a pesquisa valeu-se dos seguintes conceitos: conselho consultivo trata-se daquele em que seus integrantes têm o papel apenas de estudar e indicar ações ou políticas sobre sua área de atuação; conselho deliberativo refere-se àquele que efetivamente tem poder de decidir sobre a implantação de políticas e/ou a administração de recursos relativos à sua área de atuação; conselho fiscalizador é o que fiscaliza a implementação e o funcionamento de políticas e/ou a administração de recursos relativos à sua área de atuação; conselho normativo estabelece normas e diretrizes para as políticas e/ou a administração de recursos relativos à sua área de atuação; e conselho paritário apresenta um número igual de representantes da sociedade civil e do setor governamental. Nesta perspectiva, assume-se integralmente a informação prestada pelo informante, gestor/representante estadual, de acordo com o conceito apresentado pelo IBGE, para conceituação/classificação do conselho.

\section{Portal da Transparência}

Em relação às transferências federais nas respectivas áreas dos conselhos, obtiveram-se dados disponíveis no Portal da Transparência do Governo Federal (www.portaldatransparencia.gov.br). $\mathrm{Na}$ aba Transferência de Recursos foi selecionado o ano de 2012 e marcado a opção “por Estado/Município”. Na tela seguinte foram selecionados os estados da Região Nordeste e clicando o link "Total destinado ao Governo do Estado". A tela produto gerada de cada pesquisa do respectivo estado compõem-se de uma tabela com quatro colunas: função, ação governamental, linguagem cidadã e total no 
ano. A função foi considerada o gênero e a ação governamental e a linguagem cidadã as espécies da transferência.

Com o exclusivo objetivo de agregar os valores de acordo com as áreas dos conselhos, a classificação da transferência foi realizada seguindo o seguinte critério: a transferência foi classificada prioritariamente pelo gênero (função), quando o termo descrito no portal coincidia com a área do respectivo conselho (por exemplo, saúde-saúde; educação-educação); transferência classificada pela espécie (ação governamental/linguagem cidadã), quando não houve coincidência do gênero com a área do conselho. Por fim, a transferência classificada como "Outras" quando não houve correspondência entre gênero e espécie da transferência e neste caso, o recurso não pode ser classificado/alocado em nenhuma das dezesseis áreas de conselhos estudados. Os valores extraídos do Portal, e que compõem este estudo, referem-se a transferências discricionárias do ente federal, não incluindo-se, assim, a cota-parte tributária e o fundo de participação dos estados.

Os dados foram agregados em dois quadros para verificar a existência de interfaces Estado/sociedade neste nível de governo e como se dá seu funcionamento, de acordo com os critérios adotados pela ESTADIC (IBGE, 2012).

Quadro 1 - Perfil nacional dos Conselhos estaduais por áreas temáticas e características

\begin{tabular}{|c|c|c|c|c|c|c|c|c|}
\hline \multirow[b]{2}{*}{ Conselhos } & \multirow{2}{*}{$\begin{array}{c}\text { Existência } \\
\text { nos } \\
\text { Estados }\end{array}$} & \multicolumn{7}{|c|}{ Características } \\
\hline & & $\mathbf{R}$ & D & $\mathbf{P}$ & C & $\mathbf{N}$ & $\mathbf{F i}$ & $\mathbf{F}$ \\
\hline Saúde & 27 & 25 & 27 & 27 & 16 & 11 & 19 & 27 \\
\hline Direitos da Criança e Adolescente & 27 & 27 & 25 & 27 & 16 & 19 & 20 & 25 \\
\hline Educação & 27 & 27 & 24 & 19 & 24 & 25 & 16 & 18 \\
\hline Meio Ambiente & 27 & 25 & 24 & 24 & 22 & 21 & 12 & 23 \\
\hline Cultura & 27 & 23 & 23 & 18 & 24 & 15 & 18 & 20 \\
\hline Direitos do Idoso & 27 & 27 & 26 & 26 & 19 & 17 & 14 & 6 \\
\hline \begin{tabular}{|lll}
$\begin{array}{l}\text { Direitos } \\
\text { deficiência }\end{array}$ & das pessoas & com \\
\end{tabular} & 27 & 25 & 25 & 24 & 18 & 15 & 22 & 8 \\
\hline Segurança Alimentar .e Nutricional & 27 & 26 & 15 & 7 & 20 & 6 & 11 & 2 \\
\hline Gênero & 26 & 24 & 20 & 16 & 20 & 4 & 15 & 4 \\
\hline Direitos Humanos & 21 & 20 & 16 & 15 & 12 & 6 & 13 & 3 \\
\hline Habitação & 18 & 13 & 14 & 16 & 11 & 3 & 7 & 18 \\
\hline Esporte & 17 & 10 & 13 & 13 & 14 & 11 & 5 & 10 \\
\hline Segurança Pública & 16 & 12 & 9 & 9 & 13 & 6 & 6 & 12 \\
\hline Transporte & 10 & 7 & 8 & 5 & 7 & 6 & 3 & 7 \\
\hline Promoção da Igualdade Racial & 13 & 11 & 7 & 11 & 10 & 5 & 3 & 1 \\
\hline Direitos LGBT & 5 & 4 & 3 & 5 & 4 & 2 & 2 & 0 \\
\hline
\end{tabular}

R-Reunião / D Deliberativo / P - Paritário / C - Consultivo / F - Fundo / N - Normativo / Fi - Fiscalizador

Fonte: IBGE, Diretoria de Pesquisas, Coordenação de População e Indicadores Sociais, Pesquisa de Informações Básicas Estaduais 2012 
Quadro 2 - Perfil dos Conselhos estaduais na Região Nordeste por áreas temáticas, existência, características, valor e percentual das transferências federais em 2012

\begin{tabular}{|c|c|c|c|c|c|c|c|c|c|c|}
\hline \multirow{2}{*}{ Conselhos } & \multirow{2}{*}{ Existência } & \multicolumn{7}{|c|}{ Características } & \multirow{2}{*}{$\begin{array}{c}\text { Transferências } \\
\text { federais em R\$ } \\
\text { (2012) }\end{array}$} & \multirow{2}{*}{$\%$} \\
\hline & & $\mathbf{R}$ & D & $\mathbf{P}$ & C & $\mathbf{N}$ & $\mathbf{F i}$ & $\mathbf{F}$ & & \\
\hline Saúde & 9 & 9 & 9 & 9 & 4 & 3 & 7 & 9 & $2.417 .042 .481,00$ & $20,762 \%$ \\
\hline $\begin{array}{l}\text { Direitos da Criança e } \\
\text { Adolescente }\end{array}$ & 9 & 9 & 7 & 9 & 5 & 6 & 7 & 8 & $974.109,00$ & $0,008 \%$ \\
\hline Educação & 9 & 9 & 9 & 7 & 7 & 8 & 4 & 7 & 7.419.881.979,00 & $63,735 \%$ \\
\hline Meio Ambiente & 9 & 9 & 7 & 8 & 6 & 6 & 4 & 8 & 707.299.631,00 & $6,076 \%$ \\
\hline Cultura & 9 & 9 & 6 & 5 & 8 & 4 & 6 & 7 & $32.455 .364,00$ & $0,279 \%$ \\
\hline Direitos do Idoso & 9 & 9 & 8 & 9 & 6 & 5 & 4 & 2 & $130.300,00$ & $0,001 \%$ \\
\hline $\begin{array}{l}\text { Direitos das pessoas } \\
\text { com deficiência }\end{array}$ & 9 & 9 & 8 & 8 & 6 & 3 & 6 & 2 & $540.000,00$ & $0,005 \%$ \\
\hline $\begin{array}{l}\text { Segurança Alimentar } \\
\text { e Nutricional }\end{array}$ & 9 & 9 & 5 & 2 & 5 & 2 & 5 & - & $96.707 .580,00$ & $0,831 \%$ \\
\hline Gênero & 8 & 7 & 6 & 4 & 6 & 1 & 3 & - & $9.811 .032,00$ & $0,084 \%$ \\
\hline Direitos Humanos & 8 & 9 & 5 & 7 & 5 & 3 & 4 & 1 & 7.946.419,00 & $0,068 \%$ \\
\hline Habitação & 6 & 4 & 5 & 6 & 4 & - & 3 & 4 & $110.396 .335,00$ & $0,948 \%$ \\
\hline Esporte & 6 & 3 & 5 & 4 & 4 & 3 & 2 & 4 & $25.240 .733,00$ & $0,217 \%$ \\
\hline Segurança Pública & 5 & 4 & 4 & 4 & 3 & 4 & 3 & 3 & $355.221 .906,00$ & $3,051 \%$ \\
\hline $\begin{array}{ll}\text { Promoção } & \mathrm{da} \\
\text { Igualdade Racial } & \end{array}$ & 5 & 3 & 2 & 5 & 4 & 1 & 1 & - & $1.136 .786,00$ & $0,010 \%$ \\
\hline Direitos LGBT & - & - & - & - & - & - & - & - & 149.199,00 & $0,001 \%$ \\
\hline Transporte & - & - & - & - & - & - & - & - & $456.807 .161,00$ & $3,924 \%$ \\
\hline \multicolumn{9}{|c|}{ Total } & $11.641 .741 .015,00$ & 100,00 \\
\hline
\end{tabular}

Fonte: IBGE, Diretoria de Pesquisas, Coordenação de População e Indicadores Sociais, Pesquisa de Informações Básicas Estaduais 2012; Portal da Transparência (www.portaldatransparencia.gov.br)

\section{OS CONSELHOS ESTADUAIS DE POLÍTICAS NO NORDESTE}


Apesar desta análise concentrar-se nos Conselhos estaduais do Nordeste, uma observação a nível nacional merece destaque: Conselhos de Promoção da Igualdade Racial (13), de transporte (10) e Direitos de $\mathrm{LGBT}^{8}$ (5) aparecem em menos de 50\% do estados brasileiros. O que indica ausência de mecanismos de interface Estado-sociedade nestas áreas de atuação governamental. A situação das áreas acima é pior no Nordeste. Neste, não se verifica existência de conselhos de transporte e de LGTB, encontrando-se apenas 05 conselhos de Promoção de Igualdade Racial em toda a região.

A situação da área de transportes parece ser a mais grave, uma vez que o governo federal repassou cerca de $\mathrm{R} \$ 456$ milhões para os estados do Nordeste. Percebe-se, assim, uma acentuada transferência de recursos (aproximadamente 4\% do total de repasse das áreas analisadas) e uma grande carência de controle social. A inexistência de Conselhos nestas áreas parece indicar uma falta de preocupação do governo federal em vincular o repasse de recursos à existência destes espaços.

Observação interessante, ainda sobre a falta de controle social, é que habitação, esporte, segurança pública, promoção da igualdade racial, LGBT e transportes receberam cerca de $8 \%$ das transferências federais analisadas e possuem conselhos em no máximo 06 estados. Outro indicador é observado nas características dos conselhos de esporte do Nordeste. Dados do Portal da Transparência registram um repasse de cerca de $\mathrm{R} \$ 25$ milhões para 2012, no entanto, apenas CE, PI e RN haviam realizado reunião nos últimos 12 meses à data da realização da pesquisa, mesmo existindo 06 conselhos de caráter deliberativo e fiscalizador. O estado do Maranhão, por exemplo, recebeu cerca de 6,2 milhões de repasse do governo federal, porém não havia se reunido. Neste sentido, se a democracia deliberativa supõe a discussão pública como critério para a melhoria da qualidade da democracia, a inexistência de reuniões inviabiliza não só a influência dos Conselhos nas políticas governamentais, como também seu próprio feitio de controle social.

Comprovando o papel indutor do governo federal, os Conselhos de saúde e educação concentraram cerca de $84 \%$ dos repasses das áreas analisadas. No Nordeste, todos estes conselhos apresentaram caráter deliberativo e haviam realizado reuniões nos últimos 12 meses. Convém explicitar o conceito de deliberação com vistas a não confundilo com a teoria deliberativa proposta por Fishkin et al. A ESTADIC (IBGE, 2012) entende como deliberativo os conselhos que tem poder de decisão sobre a implementação de

${ }^{8}$ Lésbicas, Gays, Bissexuais, Travestis, Transexuais e Transgêneros. 
políticas em sua área de atuação. Tal caráter, assim, é apenas um dos aspectos da teoria deliberativa, não sendo suficiente para constatar a existência deste arranjo democrático.

Ademais, verificou-se que entre os conselhos de educação menos de 50\% tinham caráter fiscalizador. Ou seja, MA, PI, RN, PB e SE não “fiscalizavam a implementação e o funcionamento de políticas e/ou a administração de recursos relativos à sua área de atuação" (IBGE, 2012). Tem-se, assim, que até mesmo em políticas estruturadas em sistemas nacionais, os conselhos não conseguem exercer a feliz combinação proposta por Tatagiba (2002) de aliar fiscalização a deliberação.

Ainda no que concerne à fiscalização, colocada por alguns estudiosos como o lugar dos Conselhos municipais na estrutura governamental, a vertente estadual destes espaços parece não conseguir atuar neste sentido. Em 08 das 16 áreas investigadas pela ESTADIC, o caráter fiscalizador é encontrado em $50 \%$ ou menos dos Conselhos estaduais do Nordeste. Outro aspecto investigado pela pesquisa e que possui íntima relação com o controle de gastos diz respeito à existência de fundos. Para esta característica, a pesquisa aponta que os Conselhos de Direitos do Idoso, Direitos da Pessoa com Deficiência, Segurança Alimentar e Políticas de Gênero possuíam fundo em menos de 02 estados.

Conforme proposto na seção anterior, a paridade não é suficiente para garantir o equilíbrio entre Estado/sociedade nas decisões dos conselhos. No entanto, ela é condição para que a sociedade seja minimamente representada nestes espaços. Os números mostram que apenas na Saúde, Direitos da Criança e do Adolescente, Direitos do Idoso, Habitação e Promoção da Igualdade Racial há paridade em todos os conselhos estaduais do Nordeste. Em todas as outras áreas registrou-se a existência de pelo menos um Conselho sem o perfil paritário. Destaque maior para os conselhos estaduais de Segurança Alimentar, onde apenas 02 possuem esta característica. Situação grave, se entendermos a segurança alimentar como política essencial para redução da pobreza e da miséria e a sua susceptibilidade ao uso assistencialista/eleitoreiro.

Por fim, a análise do caráter normativo dos conselhos estaduais nordestinos retoma a discussão sobre o resultado das deliberações. De acordo com Moreira (1999, p.65), "O Conselho não quebra o monopólio estatal da produção do Direito, mas pode obrigar o Estado a elaborar normas de Direito de forma compartilhada [...] em co-gestão com a sociedade civil". Assim, os conselhos podem angariar um papel normativo a partir da instituição de resoluções. Estas normas tornariam as decisões vinculativas, contribuindo não só para influenciar as políticas públicas, como também para motivar a participação e 
para legitimação dos Conselhos enquanto importante instrumento democratizante. Os dados da ESTADIC, neste sentido, parecem ratificar as premissas de Tatagiba (2002) exprimindo uma diminuta capacidade propositiva por parte dos Conselhos estaduais do Nordeste. Segundo a pesquisa do IBGE, em 08 das 14 áreas que possuem conselhos no Nordeste, menos de $50 \%$ deles possuem caráter normativo.

Diante do exposto, parece notório que as características apontadas pela ESTADIC para os Conselhos de políticas estaduais do Nordeste apresentam fragilidade em todos os aspectos levantados. Inexistência de Conselhos em áreas de extrema relevância para os governos estaduais, problemas de fiscalização, existência de fundos, deliberação, poder normativo e, até mesmo, de paridade foram identificados na pesquisa.

\section{CONSIDERAÇÕES FINAIS}

As informações analisadas indicam problemas em todas as características dos Conselhos, o que afasta qualquer possibilidade de aproximação aos mecanismos propostos pela teoria deliberativa. A inexistência destes fóruns em áreas de extrema relevância para atuação dos governos estaduais - como é o caso das políticas de transporte -, assim como a não realização de reuniões nos últimos doze meses em alguns conselhos impedem a efetivação de discussões públicas. Da mesma forma, a falta de monitoramento e de transparência dos gastos setoriais, observados com os problemas de fiscalização e de inexistência de fundos estaduais em alguns conselhos, limita a capacidade de deliberação ao restringir o conhecimento da situação financeira da política em questão - elemento essencial para a tomada de decisão.

Ausência de paridade, percebida, sobretudo, na Segurança Alimentar, é outra característica que compromete a perspectiva deliberativa destes fóruns estaduais, uma vez que a falta de equilíbrio entre estado e sociedade na composição dos conselhos reduz a possibilidade de existência de opiniões concorrentes nos debates públicos. Outrossim, o poder normativo dos Conselhos configura-se como importante indicador da influência destes espaços nas políticas públicas, apresentando, no estudo, problemas em todas as áreas analisadas. A falta de caráter vinculativo das decisões enfraquece a capacidade decisória dos conselhos estaduais ao deslegitimar as preferências de seus participantes, o que afasta o poder transformacional defendido pela democracia deliberativa.

Convém ressaltar, no entanto, que áreas como Saúde e Educação, incorporadas a um sistema nacional de provisão de serviços públicos e que angariam os maiores valores dos repasses federais, possuem conselhos com maior capacidade de influenciar as políticas 
públicas. Nestes setores, faz-se necessária a realização de estudos de caso, com vistas a conhecer com profundidade cada conselho, sobretudo no que diz respeito à autonomia das suas decisões, à existência de ideias concorrentes e à possibilidade de mudança de opiniões ao longo das discussões públicas (FISHKIN, 2005).

Os dados, portanto, sugerem a necessidade de aperfeiçoamento dos conselhos estaduais do Nordeste. As deficiências em características básicas para seu funcionamento restringem seu potencial de qualificar as decisões por meio de um diálogo público consciente e com a presença de ideias concorrentes. Diante deste cenário, o governo federal aparece como ator fundamental, podendo induzir a criação e o aprimoramento destes espaços institucionalizados de participação.

\section{REFERÊNCIAS BIBLIOGRÁFICAS}

ABRÚCIO, F. L. Os Barões da Federaşão: Os Governadores e a Redemocratização Brasileira. São Paulo: Hucitec, 1998.

ARRETCHE, M. Políticas sociais no Brasil: descentralização em um estado federativo. Revista Brasileira de Ciências Sociais, vol. 14, n.14, jun.1999. p.111-141 (2004). Federalismo e Políticas sociais no Brasil: problemas de coordenação e autonomia. Revista São Paulo em Perspectiva, vol. 18, n.2, pp. 17-26.

BRASIL. Congresso Nacional. Constituição Federal. Brasília. 1988.

BOBBIO, L.. Entre o reflexo e a proposição. Dilemas sobre o encerramento dos fóruns deliberativos. Sociologias. Porto Alegre, ano 14, n.30, mai./ago. 2012. p46-69.

CORTES, S. V. Viabilizando a Participação em Conselhos de Política Pública Municipais: arcabouço institucional, organização do movimento popular e policy communities. IN: HOCHMAN, Gilberto; ARRETCHE, Marta; MARQUES, Eduardo (Orgs.). Políticas Públicas no Brasil. Rio de Janeiro: FIOCRUZ, 2007.

CUNHA, E. O potencial de conselhos de politicas e Orçamentos Participativos para o aprofundamento democrático. IN: DAGNINO, Evelina;TATAGIBA, Luciana (Orgs.). Democracia, Sociedade Civil e Participação. Chapecó: Argos, 2007.

DAGNINO, E. (Org.). Sociedade civil e espaços públicos no Brasil. IN: Sociedade Civil e 
Espaços Públicos no Brasil. São Paulo: Paz e Terra, 2002.

ELSTER, J. O mercado e o fórum: três variações na teoria política. In: Democracia Deliberativa. Editora Singular: São Paulo, 2007.

FISHKIN, J.; LUSKIN, R. Experimenting with a democratic ideal: deliberative polling and public opinion. Acta politica. Vol.40, 2005.p.284-298.

GERRING, J. The Case Study: What it is and What it Does. In: Carles Boix \& Susan Stokes (eds.). The Oxford Handbook of Comparative Politics. Oxford: Oxford University Press, 2009. pp. 19-33.

GOHN, M. da G. Emponderamento e participação da comunidade em políticas sociais. Saúde e Sociedade. v.13.n.2.maio-ago, 2004, p.20-31.

GONÇALVES, R. da R. Políticas Habitacionais na federação brasileira: os estados em busca de seu lugar. Dissertação de mestrado, Escola de Administração de empresas de São Paulo da Fundação Getúlio Vargas, 2009.

HELD, D. Deliberative Democracy and the Defence of the Public Healm. In: Models of Democracy. Stanford University Press: California, 2006.

IBAM, IPEA, COMUNIDADE SOLIDÁRIA. Conselhos Municipais e Políticas Sociais. Rio de Janeiro, 1997.

IBGE. Pesquisa de Informações Básicas Estaduais (ESTADIC), 2012.

INSTITUTO DE PESQUISA ECONÔMICA APLICADA. Brasil em Desenvolvimento: Estado, planejamento e políticas públicas. Instituições Participativas e Políticas Públicas no Brasil: Características e Evolução nas Últimas Duas Décadas. Brasília: Ipea, 2010, 270 p. 3 v.

MOREIRA, M. T. V. Instâncias deliberativas dos sistemas descentralizados e participativos das politicas públicas de cunho social: contorno jurídico dos conselhos. IN: INFORMATIVO CEPAM. São Paulo: Fundação Prefeito Faria Lima, 1999.

RAGIN, C. The Variable-Oriented Approach. In: The Comparative Method: moving beyond qualitative and quantitative strategies". Los Angeles/London, University of California Press, 1987.

SMITH, G. Mini-publics: assemblies by random selection. In: Democratic Inovations. Crambridge University: NY, 2009. 
SOUZA, C. 'Estado do Campo' da pesquisa em políticas públicas no Brasil. Revista Brasileira de Ciências Sociais, v.18, n.51, 2003. p.15-20.

TATAGIBA, L. Os Conselhos Gestores e a Democratização das Políticas Públicas no Brasil. IN: DAGNINO, E. (Org.). Sociedade Civil e Espaços Públicos no Brasil. São Paulo: Paz e Terra, 2002. 